\title{
Abuse of bets unnecessarily the right to disturb the unilateral contracts
}

\author{
Seyyed Bagher Seyyedy Bonabi ${ }^{1}$, Mehdi Abdollahi ${ }^{2}$ and Akbar Bashiri ${ }^{3}$ \\ 1 Corresponding Author: Assistant Professor, Department of Law, Bonab Branch, Islamic Azad University, Bonab, Iran. E-mail: \\ seyyedy_bonab@yahoo.com \\ 2 PhD Student, Department of Law, Maragheh Branch, Islamic Azad University, Maragheh, Iran. \\ 3 Assistant Professor, Department of Law, Maragheh Branch, Islamic Azad University, Maragheh, Iran.
}

\begin{abstract}
Today, as a priority economic, social other causes one party to the contract is concluded to impose some conditions to the other party acts the opposite side due to economic weakness or need for imposing them or Premier status such provisions are included in the contract that is not compatible with the principles of safe deposit rights, including and such a condition according to the free will of the other side and there and certainly if the person has a free will to investigate was never accepted it was not and in practice caused the damage and the imposition of arbitrary conditions is superior. One of the cases of abuse of these cases, the Bet is a discredit to disturb the one-way contract most contracts today there which sometimes causes the weak contractual party will be huge losses this paper seeks to study and determine the effects of such provisions in contracts Rules.
\end{abstract}

Keywords: contract, the conditions imposed, rights, poke, abuse, harmless

\section{INTRODUCTION}

Jurisprudence rights including the rights of the rights of Iran's ability to stir a variety of ways. Stir legal action that will require the authority.

The inclusion of a one-way Bet to avoid disrupting contracts, but the contracts are common practice for courts to cause problems.

In Iranian law and Article 448 of the Civil Code rights from financial rights (SAFAI, 2001). Also approved this point. According to the principle of party autonomy and rule skill any attempt to right holders can poke their rights unless such is contrary to the rules (public order, law and ethics is good) is (MOLOUDI, 2000). But what is discussed, the abuse of this Bet through the imposition of one party on the other side of Contract. For example, if the seller was aware of the defect object of sale due to the urgent need for the product bet the buyer to avoid disrupting ask unilateral agreements without such consideration provided

And for example be deducted a percentage of the price, to be sure, the buyer if the free will expressed in the survey had bet but it was not willing to accept the inevitable, due to their status or superior seller has accepted it. In accordance with the principle of party autonomy and Article 10 of the Civil Code filed to be included in the contract provided that all necessary contracts and the cancellation clauses and not revoked, such a condition is true and the executive, but sometimes economic power or social conditions in the contract using one of the parties to the contract is included in the contract. Bet that the other party will have to accept the contract without the consent or will of the he was apparently 
accepted that on the one hand and on the other hand does not want to accept it And the need to contract it has accepted the validity or invalidity of the condition in these cases and that no clear is the situation and what will be the fate of such a contract?

The principle of autonomy in regulating social relations as the base is used in personal relationships will person that he is limited to what one wills is fair and legal acts in personal relationships will of the person that bound him what one wills is fair and legal acts more than others since everyone can recognize your profit or loss is not possible closing of unfair contracts and rights should respect the provisions of the consent of the two parties but this concept is not commutative justice.

Kant argued in the case that someone else decides about the injustice is always possible, but when he wants something else for me there is no likelihood of any violence (KATOUZIAN, 2001). But nowadays one of the parties to the contract with the priority economic, social and impose their opinion to the opposite side with unpardonable inequalities in contractual relationships and the emergence of additional contracts from the pre-written, commutative justice is not pro-poor because the poor condition of his contract and become a victim of negative economic conditions. In the past French law to the effect that the rule entitled ((anyone under the contract talks is fair)) that no way for any modification of the contract in the event of abuse on the other hand, the contract closed but lawmakers to review the rule faded since then like other regulators developed countries took several actions in order to create a relative balance in the contract. Adapting to wager that one of the parties to abuse their dominant position to insert it in the contracted. This condition, known as ((clauses abusive)) have been identified in the French legal system is in fact one of the contractual balance. This new method with other methods of balancing deal the new trend as consumer rights, which is one of the important legal in developed countries is institutionalized. Another example of the conditions imposed, insert a condition in the marriage contract is one way to avoid disrupting sometimes with how the parties will be imposed with respect to certain provisions. Obliges contracts with abuse of a dominant economic conditions or weakness of the contract will not attempt to impose such a condition. According to the circumstances and conditions of the contract parties, imposed insert it seems this paper seeks to study the issues and the provisions of such a condition in the contract.

Subscribe to respect the rights of individuals to have contracts signed with the original shall be accepted but if a condition be imposed that sentence is unconscionable to implement it, should be amended or revocation. In common law, except in special cases such as whitewashing, duress, undue influence, can judge wrong in the contract that the parties have signed it with his will to intervene and such police balancing the parties' contractual role to play because the assumption is that consensual achieved not suffer from the inability to have. Because it is the responsibility of those who retain their interests and if a contract is signed, which has adverse conditions he must be blamed who has committed such an act (SHIRAVI' 2002). Surely absolutely agree with this view is difficult because sometimes if one of the parties has signed such a 
contract with their will but superior position to the other party or his poor economic status or other causes would accept all the terms of the contract including the provision been imposed while the above views would accept his loss and will have negative effects.

\section{FIRST TOPIC: PROVISO AVOID DISTURB- ING CASES OF ABUSE OF UNILATERAL CONTRACTS}

The first paragraph: cases of abuse of a condition of unilateral contracts in order to avoid disturbing the conventional balance.

Although the parties in accordance with the principle of party autonomy and freedom of contract can conclude the contract in accordance with their will and conditions in which indicating that their interests in the wake of the idea that each party to drycleaning more benefits but in some cases, such abuse has taken on color conditions severely undermines the position of one of the parties. One of the terms, conditions preventing disruption of unilateral contracts but in some cases, such abuse has taken on the color condition severely undermines the position of one of the parties. One of the terms, conditions to avoid disrupting oneway contracts which is not imposed in all cases, but compared to some of the conditions is quite unfair and an abuse case the present paper is aimed at studying the ruling and its consequences.

To avoid disrupting a contract clause inserted in contracts cannot assumed illegitimacy in the first stage or the invalidity of such provision to all the conditions it should be investigated which of its various manifestations provisions will be imposed? For example poke the price of delay or Parlia- ment is not normally imposed but in the case that the seller is aware of the product defect and to escape the consequences of its resorting to this condition, it can be said that such a condition should be imposed on the legislator to remedy it because the legislation will allow deceive others for more profit. The legislator goal of balancing contractual rights and prevent harm to the victim contract and if one party uses its dominant position or to exploit the poor economic situation of the other party or even of urgency them to act provisions that given the circumstances of the contract conditions imposed on the parties to be considered, such a contract should be modified (removal condition) and ignoring its condition to help to create balance. British law since ancient times believed in the strength of their contracts unless the contract in the case of whitewashing, duress, mistake or undue influence to be signed or one of the parties does not have the full capacity and the other party is aware of his situation in all these cases, the contract shall not be binding to the damaged party and the court of justice in some cases prevent the execution of such contracts. For example, in contracts relating to inheritance heirs inherit some of their future cash received in exchange for dim sum that would be given to others, court to intervene and to support it in the contract in case heirs earl of sandglasses v. mishap it argued that the assignor at the time of conclusion of the contract in the economic situation lived and was not able to understand the nature of the contract, why should such an agreement be amended or revoked (ANGELO \& ELLINGER, 1992).

Or in cases where one of the parties will suffer due to the deception, the court can 
intervene in the contract for example, in a case of a poor man that his land is worth 1700 pounds versus 200 pounds, transferred to another, the court arguing that the buyer of poverty and illiteracy, abuse and benefited the seller, and the situation has been taken against the dealer and the dealer has not been able to promote their own interests, be adjusted contract and the involvement of the fetus ((inequality in bargaining power)) to be drawn. In English law that the court should not intervene in all contracts because most contracts signed as a result of competition in the market, and only the intervention of the courts in cases where there is gross inequality transactions between the parties. In fact, the law in England in the seventeenth century, however, the attention of the English courts were unfair contracts therefore, sometimes the whole contract or some of its provisions were set aside, but this theory was popularized never failed to find its firm position in English law. In 1974 the Court of lending authority to intervene in this agreement is that if necessary, if the contract according to the conditions governing the contract is exorbitant and unfair to amend it. In Article 138 of this law criteria for recognition of loan contracts have been rendered unfair that if the loan applicant or his relatives are required to pay a significant sum or is totally contrary to the principles of fair terms, such a contract is unfair. In recognition of contract and unfair conditions in addition to external factors such as interest rates or the time of conclusion of the contract, the economic situation of the borrower, his business experience, age, and mental health status is considered.

Second Paragraph: abuse of bets avoid disrupting a contract to poke rights White- washing Lawyers believe that the rights of the right type and the result is disturb and such reasoning, the law explicitly poke them and the ability to inherit property (Article 448 of the Civil Code). Rights because legal action is needed, but most lawyers and jurists will be entitled to certain rights are agreed on the impossibility poke this paper attempts to examine some of these rights when such a condition is imposed. The jurisprudence also respect the right to legal and do not believe in the rule of law because the will is the rightful owner of poke (BIGDELI, 2000). However, although rights are basically right but sometimes aspect of his sentence and cannot poke for example, one of these cases was the right whitewashing that the legislator will not be allowed to deceive others aware that the abuse of ignorance or weakness of others and avoid disturb one-way contracts with the condition of the right to be left to bear the consequences. Stir legal rights unilateral action that does not need the consent of the other party and what is discussed undue hesitation in the poke such a right. For example, the legal basis for the rule of law is considered harmless that the parties to poke it to their loss and such loss cannot be regarded as inadmissible and the nullity or invalidity of such a contract with its condition have different views:

1- Nullity of the marriage spread bets and contracts will also lead to its invalidation in this sense it can be said that criticism usually the condition is related to the contract and the contract does not affect the validity and invalidity of the condition (IBRAHIMI, 2001).

2- If the contract is invalid does not work properly.

If the contract is invalid if damage to the 
unit and void contract and in other cases not contract proof and to prevent the loss of someone who has been in his favor condition can be respect in accordance with Rule safe for him to be terminated provided that the condition is not aware of invalidity. In other words, when the contract contains ((with the proviso installment of the price)) is nullifies the contract. In these cases because they are required by their condition imposed committed to eventually be sent invalidity of the condition will not be supported.

If the rule governing such a condition is harmless in case it may be objected although the above requirement is imposed only in favor of one of the contracting parties is not per additional but the other party is free and has supplied its loss or damage caused by his own actions. Although harmless rule does not negate the loss sentence when it is in fact the implementation of realized losses is due to the execution legislator no harm in that alleged action is required, but it can be said that sometimes people do not benefit from the expertise and also does not know bet or when relatively economically equal, adherence to the rule action is not fair. But if they were in the same economic situation and the other person was acting to their detriment, the fair seemed in fact this situation has come about conditions imposed this sentence is a clear example: ((The parties are free to accept life as much as they are free)). The underlying principle of harmless bet imposed penalty clause should not apply. Another problem that may come to mind harmless rule denies the necessity sentence and who is also stipulated in his favor by eliminating the requirement to terminate the contract and committed, will incur losses because he was demanding the original contract. In response to this objection is to say (KATOUZIAN, 1997), losses of lost interest on the secular sense. If not legitimate and respectable and studying it is illegitimate, customs not harm it, such as usury interest preconditions relying on the economic position of one side and the other side has been taking advantage of conditions that such a condition is not respected by its removal does not disturb the economic balance of the parties. And holy law does not mandate which has suffered harm others and that is the right to terminate and the need for him to be removed, not for someone who is favor bet that such a condition is imposed and removed it will not incur losses. In fact ((Believers in their own terms)), although the general rule will apply to all provisions the provisions contained in scope and will not be imposed against the real subject is included in the contract does not cover and such is not a necessary condition to run.

Article 448 of the Civil Code states appearance this means that all rights can be shot down. This consensus lawyers and except for a serious opposition (LANGROODI, 1998) against at least not in its brevity (SAFAEI, 2004). Apart from the possibility of legal rights in a poke, poke deterrent sentence that implies a permit or prohibit rights do not exist. Including the right to assembly, the right animals, reservation, to deceive, to delay, defects and seems to be following the right vision and the right general rule "the rightful poke tricks" and permit individual rights poke, poke them all is permitted. That is strong opposition among lawyers. Perhaps the most important is Langroodi disagree doctor. They believe insertion of such a provision is void and nullifies the contract. Here is a summary of 
their arguments.

According to the first paragraph of Article 232 of the Civil Code provision contrary to the requirements of the contract is void and nullifies the contract. On the one hand Article 448 of the Civil Code and he believes the opposite is harmful nature of contracts: ((law Article 448 has made a big mistake.... Stir deterrent rights clause contrary to the requirements of the contract itself is harmful. Such a condition is corrupt and corrupt sale....In this case should warrant the annulment of Article 233 and that such a sale.... condition poke the best examples of deception rights inhibitor)) (JAFARY LANGROODI, 1998).

In other words, they believe, what is the harm inherent in contracts, balance and parity obligations of the parties and if all rights not ignore the other hand, in fact, the law itself baseless and worthless identical and equivalent lost. Especially the right whitewashing and deception, etc. that somehow guarantees the rights of the parties and then poke it gone sanction infringement of the contract and if there is no other obligations. How this requirement is a commitment, the other party has the right whitewashing and deception front side and the other side cannot terminate the deceived and cheated deal, this certainly leads to deception in the transaction and puts the parties in an unequal situation, forge law enforcement philosophy against loss and will of the parties and the removal and disposal of this instrument, breach of contract and it is virtually no enforcement. In response to these comments it can be said there is a requirement to avoid disrupting one-way contracts deception because sides with knowledge of such a condition was to poke it and the assumption that a counter- party to a fault with science or whitewashing the seller will attempt to poke it, deceive and loss not consciously perceived and acted according to the rule action to their detriment, on the other hand, other rights such as the right to poke their but in the benefit of a condition or need to exploit the weaknesses of the other side he insists insertion of such a provision, aspects of the rule imposed on their condition and harmless so long ignored and deleted and in both cases it has no element of deception in trade. So in the poke whitewashing the truth can be said that cheated the opposite side of whitewashing could not ignore their rights is incontestable, but the main problem is obvious, that poke contract and to be aware of Whitewashing happen. Some lawyers believe since whitewashing is prohibited by law, and even in some cases criminal punishment is prescribed for it, poke it right is contrary to public policy and void, some professors, such as doctor Langroodi believe, that this condition was irrationally and therefore is invalid.

As a result, if the document is said to be the deterrence rights should be disregarded, whitewashing including the right to be in front of some professors such as doctor emami respect to the correctness of such conditional

((Sale sides May, in their contract a condition of sale arises rights such as the right flaw in the contract, fraud, Whitewashing and Abuse yet to be overthrown. Although there may be provided against ignorant)) (EMAMI, 1944). So lawyer's dominant view is that if the contract stipulates that the right to void Whitewashing is not the cause of nullity of the contract. But such condition or useless or illegitimate, its bet will be void. So poke whitewashing the right to 
know the truth to deceive the other hand, was a clear example of a condition imposed and such a violation cannot be done and invalidation condition has not spread to the contract and the contract will continue to keep all your effects and need to be implemented between sides.

Third Paragraph: Abuse of bets avoid disrupting one-way contract in order to poke the right to fault and legal punishment in spite of the fault. Inform the client after the fault has definitely could void his right. The difference starts from there, that are in the contract or hinder the rights poke or it clear that they have the right to poke flaw in the contract. Some lawyers believe, it is true that the customer "risk" admitted that if the product was defective, of their right to battle, but the risk has not been about conventional fault out of the ordinary and obvious fault with this version if the poke the contract all rights, Or even the fault was clearly poke and after the transaction turned out to be too conventional product is defective and has significant fault, the customer will be right.

In contrast, some lawyers poke absolute rights, including gross and simple to know whether any flaws. In 1308 the Supreme Court by a vote number $1218-348$ has provided the following comments: ((poke right outside the usual fault, including defects is not)) (BAZGIR, 2000). Some lawyers believe with the right to poke fault, absolutely legal punishment has been shot down and the buyer is not right to receive compensation payments, but such reasoning was not correct and also it does not accept the court process in verdict no. 7-26 / 71 of court stated: "poke rights contained in the document is not related to demand compensation and the possibility of terminating the transaction is not a barrier to demand compensation." Thus, when in normal mode than buyers of any kind imposed in a poke there is no legal right to claim compensation shall not be removed, a fortiori when the fault condition is imposed and compensation has not been annulled and the buyer can terminate the deal, because someone who has bad faith in contract law and abusing its position to impose the condition does not support do not loss the other hand, the conditions imposed equivalent to the condition is not entered and by eliminating the requirement to prevent excessive demands, he will not have an effect on the validity of the contract and its effects. In the case that the seller is aware of the faults and in spite of the fault and without imposing conditions to poke deduct the transaction shortly thereafter fault, is a clear example of abuse.

Fourth Paragraph: Abuse of bets avoid disrupting a contract to poke the gross deception

Lawyers in a poke right of deception after deception by the buyer not hesitate the location of a bug that has been stirred in the contract or to assert all rights overthrow the trick or the contract is emphasized that the parties have the right to overthrow the gross deception, in some of the contract in addition to gross deception poke shot down right gross deception that some lawyers believe, poke in cases where rights have been deterred This is a gross deception. Deception outside the scope of conventional multiplier is normally contained within the consent sides and includes all rights not poke and argue that: ((the phrase "subject poke" conventional deception, and if someone "gross deception" may be, the topic poke wrong and legal acts unilaterally 
in the current rule is wrong ${ }^{1}$ in this case can be made that if the difference between the price paid, Waives the right condition and shall be disregarded. Some legal scholars, including Imami doctor citing Article 448 appears to correct this condition know. In the case where the parties to circumvent gross, egregious lapses are also among lawyers is there are two theories: Some are made to verify the condition and waives the reasons for their opinion as to the following:

The rule refers to a person who has faith must be faithful, the necessary contracts, refers to Article 448 of the Civil Code to poke All rights and against opponents who advocate the abrogation of the right to terminate survival are provided with the reasons for that condition is irrational poke and the parties are not free to self-harm and harm to person and is a clear example of such a condition but the condition appears poke the right lure, but inside the administration and for the same reasons in denying the possibility of whitewashing the whitewashing was expressed poke, poke the right as fast as possible can be rejected.

This would also contrary to good morals set forth in article 960 BC is causing deception in trade. Safai doctor believes: "If there is a gross deception, of swindle when can, to terminate the contract, which implicitly or explicitly reserves the right to not poke." This sentence their desire to be first, the validity of condition shows. Because sides have explicitly poke a gross deception. According to the quoted passage from the same doctor Katoozian also be used. Because the basis of their sayings, exposure or lack of consent on the condition Related

\footnotetext{
${ }^{1}$ Katoozian, ibid, No. 983
}

parties. If you really poke a gross deception by mutual consent of sides is placed in the circle of what is allowed to poke it and correct the condition? According to the decision of the Supreme Court on $01 / 18 / 72$ to the tenth branch number 20/10 verdict: ((Since the lawsuit whereby sales invoice documenting all rights including the right to deceive the supreme been shot down side, resorting to the trick without legal status has been detected.)) According to the decision of the third branch of the Supreme Court, dated 05.07.87 No. 410/3 in land subject to half the price of the transaction was and where all rights were violated, including deceit, deception and health condition to poke right infringement, ruling that the validity of the transaction. According to the decision of the General Court branch 6 and 7 branch Appeals Court on 03/27/75 to protest protestation No. 541, which was referred to realize a gross deception, has been rejected. In this context the court is not as effective protest protestation. Because of all the rights in the contract poke supposed to have been the right of gross deception. By a vote of the eighth branch of the Supreme Court, No. 562/8 dated 10.10.69 to indicate normal sale and the contents of the file with the correct sales poke All rights invoking the right to terminate the contract between the parties, and is not correct. 23/10/70 28/12/69 vote branch 22 of the Supreme Court and Court branch etc. (BAZGIR, 1379) imply the same meaning.

Usually precedent because the parties will agree and without going into the issue of whether this condition with the consent and will of all parties or not? and whether such a condition is imposed or not or even regardless of the gross deceit and deception 
in the case of more egregious claims the right to refuse the rights provided poke them. So in either case whether or not a gross deception more egregious deception and ignorance of the buyer to pay in the event that the condition imposed Indeed, the right shall not be removed.

\section{THE SECOND TOPIC: ORDER TO PREVENT ABUSE OF THE CONDITION DISRUPTING A CONTRACT}

The first paragraph: invalidity of the condition poke all rights

Recognizing that such a condition should be imposed on the parties in the contract and the following elements to be considered when awarding contracts carefully in different cases, conditional sentences imposed and will then examine it. Age, education, knowledge and professional expertise that is claimed that the condition imposed.

- The skills and performance of contracts

- Deal economic situation, and particularly so if the buyer is able to supply the same goods from another source or not?

- If the contract is clearly aware of the condition or does not understand its meaning or according to its reluctance to accept the other person or situation, such a condition has been imposed in fact, although the contract but because the other side does not know or according to a particular situation without its consent override this requirement is accepted.

However, due to the condition of nullity of the contract is and what impact and indeed whether this condition is invalid because it was illegitimate or as otherwise applicable requirement, or it is the nature of the contract will be considered later.

A) Revocation clause because the clause is contrary to request

In the case of one-way bets avoid disrupting said contracts cannot be imposed at all the alternatives and is void in all cases but the parties may be informed of the flaw after whitewashing or other authority and perfect will acting in accordance with the rule violated its own detriment and that there is no doubt on the validity of such an act or the invalidity of the condition to spread all rights but only flaw on the part of the owner's rights, including the right not aware of it or whitewashing or gross deception that in this case the provisions of this law only applies in these cases is void and has no effect. What is important would be the effect of invalidity of the condition that requires analysis is that such a condition is contrary to the requirements of the contract or not? It seems such a condition is not contrary to the requirements of nature swap contracts in any one of the pillars of contracts without prejudice but as an additional condition that a party intending to exploit the situation by exploiting the opposite sides the original contract did not interfere with removal and marriage still continues to survive and remove it, ignorance will not be bilateral. And if we considered it contrary to the requirements of the contract term, invalidity or there is no effect on the validity of a contract and contrary to the requirements of all applicable legal requirements contract is considered acceptable. Some rights violations of the kind of poke and destroy the vicious considered know it. While poke rights of destroying something it's not because the contracts fulfilled, poke it will not be a problem with.

In fact, the lure of selling to the right of disposal is not to be clear in the absence of the right lure for the right to order is legal 
and deceit and the rule of law on the subject has no external threads.

B) Invalidity condition due to the illegitimacy of the condition poke all rights

The jurists defined three factors considered illegitimate condition and that condition may be illegal:

1- Is contrary to Scripture and tradition

2- lawful to make forbidden and forbidden to make lawful

3- Bet itself is not permissible (ZAHEERI, 2011).

Bet carefully to avoid disrupting a contracting party to say: Bet in general and in respect of all rights is not illegal and is not compatible with the definition of serious doubts about some of the rights, including whitewashing, flaw, is a gross deception. Although the right to poke rights and principle, but in some cases such as the above aspects and deemed illegitimate verdict and why the legislator and the legislator will not be allowed to deceive others. Including those on non-corrupt illegal clause is corrupt or affect the validity of the contract was void and simply bet and its meaning is nothing but a lack of commitment on the condition of not poke rights in the abovementioned examples. Legislative procedure in transactions and contracts relating to property law, is that the private interests of individuals involved in this situation shows and more freedom for individuals and only in exceptional cases such as these rights that limit.

Second paragraph: Modified Bet avoid disrupting a contract

A) Reform Principles poke all rights Bet

According to the principle of party autonomy and freedom can be agreed provided that void and nullifies any non nullifies or invalidates be included in contracts but as was determined in previous discussions, some aspects of the conditions imposed by the and not solely because the parties agreed without being aware means or consent in accepting it is effective and advantageous position opposite sides or need has been Bet in the contract be respected. All rights imposed on the other hand cannot be regarded as invalid agreement on it but it can be modified, the withdrawal of certain rights, including the strength of the circle of transactions and respect for both parties added. For example, when the terms of the contract and it should be investigated which of them is imposed and in this study, factors such as the bargaining power of the parties, economic power, financial needs, conditions and circumstances prevailing at the time of conclusion of the contract conclusion be considered and if some of these rights with regard to the above seemed forced, remove it and circle the parties, including the Bet to be remedied. The rationale for the reform can be considered harmless rule no one should contract in Islamic law as a means to ensure their greed and harm to let him And nor should the person who deceived others by imposing Bet poke the flaw with the world of the flaw is or whitewashing and deception in the transaction are supported. In fact, Bet avoid disrupting a party to the contract has not been imposed in the case which is equivalent and not be subject to general warrant was invalid but when there is no difference instead of just the interest of one party and by imposing an undue disadvantage to the other party in certain circumstances the legislator should not enter personal support was Bet in his favor And by deleting Bet detriment to the other party the right to terminate not logged in and therefore 
should adhere to the contract.

B) Modify the Bet to avoid disrupting a contracting circle

As previously stated Bet does not prevent the disruption of unilateral contracts are false and have been imposed only to some rights and eliminating the Bet in which the material can be real will of the parties to what is acceptable is located respected them Obviously, the above requirement is not imposed on all aspects of the law, and if Bet is generally omitted this practice would be unfair and wrong. So to correct this Bet in the area of the flaw, whitewashing, fraud, gross and poke other contractual rights can be helped balance and none of the parties will not unduly suffer losses. In fact, it can be analyzed whenever the one-way Bet to avoid disrupting the terms of the contract have the right Whitewashing because after whitewashing the knowledge that it can be overthrown and before that person was not aware of whitewashing how it has shot down as if aware that it will not accept it. As well as the right of that person's flaw or gross deception after the transaction is aware of it and before that at the time of conclusion of the transaction or hidden and the person is unable to inform and aware of it, so if you are aware of it and downed it with their will be no hesitation in accepting it but in the case after the conclusion of the transaction and Bet that the person is aware of it except to remove the Bet is not relevant and it rule ((fulfill the condition)) is retractable.

\section{CONCLUSION}

Abuse of bets avoid disrupting a contract today, in most contracts, especially contracts between the parties there with the printed version that the parties are often not aware of its meaning whether or not due to their economic situation or emergency or superior position to accept the other side of suicide.

However, such a condition in some instances, such as flaw, whitewashing, fraud and was forced reservation and the other due to lack of awareness or ignorance of defects in sales whitewashing the opposite side or the gross deception in the sale of the contract after it becomes aware, It will be healthy and cannot accept such an illegitimate and void, provided that it does not affect the validity of the contract signify the establishment. Exploited the Bet is that no equivalent contractual imbalance gone and judgment of invalidity of such provision because of the illegitimacy of certain rights and good Bet is corrected.

\section{REFERENCES}

ADL, MUSTAFA. Civil rights, Tehran, Bahrololum 1993.

AHMAD ZADEH, ABOLFAZL. ZANJANI, AMID, overviews provisions of law. Jurisprudence Fundamentals of Islamic Law Journal, Vol. 44, No. 1, 2011.

ANGELO; ELLINGER. Unconscionable contracts, a comparative study of the approaches in England, France, Germany and United states. Comparative Law Journal.1992.

BAZGIR, YADULLAH. The rights of its Rules, Tehran, Ferdowsi Publishing, 1379 BIGDELI, ATAOLLAH. Poke rights law hiatus from Shiite Iran, Volume 11, No. 31, 2010. CATOZIAN, NASSER. General rules of contracts, vol. 3, no 2, Tehran, 1998. EMAMI, ASADOLAH. ABDI, SADEG. Analysis of legal jurisprudence exclude contractual 
liability, Higher Education Complex Qom, Series first, the second no, 1998.

EMAMI, HSSAN. Civil rights, publishing Islamiyah, 1966.

GAEEM MAGAMI, ABDUL MAJID. Rights and obligations, Tehran, Tehran University Publishing, 1956.

IZANLOO, MOHSEN. A condition limiting Overthrow of responsibility, Tehran, publishing Enteshar, 2003.

JAFAR LANGROODI, MOHAMMAD JAFAR. Detailed in terminology, vol. 1, Tehran, GANJE DANESH, 1998.

MOLOUDI QLABCHI, MOHAMMED. Poke a right that has not yet occurred, Faculty of Law and Political Science, No. 47, 2000.

SAFAIE, SEYYED HOSSEIN. Civil Rights Foundation, vol. 2, Tehran, MIZAN published in 2004.

SARDUEE NASAB, MOHAMMED KAZEM POUR, JAFAR. Unfair component of the contract. Justice Journal, Vol 75, No. 75, 2011.

SHIRAVI, ABDULHOSSEIN. Theory of unfair contractual terms in common law rights, with an emphasis on the rights of England, America and Australia. Journal of Higher Education Complex Qom, Year 4, No. 14, 2002.

SHOBEIRI, ZAHRA. Compared preconditions illegal clause contrary to the requirements of the contract. Legal Research, No. 4, 2006.

ZAHERI, ABDOLAMIR. Poke statutory rights in law and jurisprudence, the 119 and the 120, Association Journal, 2011.

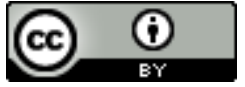

License information: This is an openaccess article distributed under the terms of the Creative Commons Attribution License, which permits unrestricted use, distribution, and reproduction in any medium, provided the original work is properly cited.

Article received on June 09, 2017.

Evaluated July 04, 2017.

Accepted on Jully 04, 2017.

Published on August 18, 2017.

How cite this article (ABNT):

BONABI, Seyyed Bagher Seyyedy; ABDOLLAHI, Mehdi; BASHIRI, Akbar. Abuse of bets unnecessarily the right to disturb the unilateral contracts. Estação Científica (UNIFAP), Macapá, v. 7, n. 1, p. 09-20, jan./abr. 2017. 